BLS 34, No 1 2008. DOI: http://dx.doi.org/10.3765/bls.v34i1.3561

(published by the Berkeley Linguistics Society and the Linguistic Society of America)

\title{
Total Identity in Co-occurrence Restrictions
}

\author{
GILLIAN GALLAGHER \\ Massachusetts Institute of Technology
}

\section{Introduction}

In this paper, I look at languages that require complete identity between certain classes of non-adjacent consonants and discuss the implications of these data for the Agreement by Correspondence (ABC) analysis of long-distance consonant agreement (Hansson 2001, Rose and Walker 2004).

Some languages exhibit what MacEachern (1999) calls the TOTAL IDENTITY EFFECT. In languages of this type, pairs of similar segments are prohibited from cooccurring in a root while identical segments may cooccur.

$$
\begin{aligned}
& \text { Chol (Mayan: Aulie and Aulie 1978, Coon and Gallagher 2008) } \\
& \text { non-identical ejectives: } \quad \text { *ts'-k', *ts'-t', *p'-k' } \\
& \text { identical ejectives: } \quad \checkmark \text { ts'-ts', } \checkmark \text { k'-k', } \checkmark \text { p'-p' }
\end{aligned}
$$

(2) Muna (Austronesian: van den Berg 1989, Coetzee and Pater in press)

$$
\begin{array}{ll}
\text { non-identical homorganic: } & * \mathrm{~m}-\mathrm{b},{ }^{*} \mathrm{~b}-\mathrm{p},{ }^{*} \mathrm{p}-\mathrm{f} \\
\text { identical homorganic: } & \checkmark \mathrm{m}-\mathrm{m} \checkmark \mathrm{b}-\mathrm{b} \checkmark \mathrm{p}-\mathrm{p}
\end{array}
$$

In (1) and (2), a certain class of non-adjacent consonants (ejectives and homorganics, respectively) must be totally identical in order to cooccur.

Total identity requirements contrast with another phenomenon where similar non-adjacent segments are required to agree in a single feature only. In Chumash, for example, stridents must agree in anteriority, but may disagree in other features.

$$
\begin{aligned}
& \text { Chumash (data from Hansson 2001:58, taken from Applegate 1972) } \\
& \text { Sapit }{ }^{\mathrm{h}} \text { olit /s-api-t } \int^{\mathrm{h}} \mathrm{O} \text {-it/ 'I have a stroke of good luck' }
\end{aligned}
$$

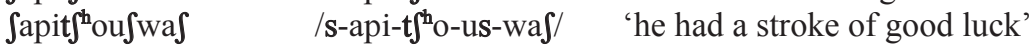

$$
\begin{aligned}
& \text { hasxintilawas /ha-s-xintila-waj/ 'his former Indian name' }
\end{aligned}
$$

In this talk, I argue that total identity is formally distinct from partial identity. In the $\mathrm{ABC}$ framework, total and partial identity are analyzed uniformally as effects 


\section{Gillian Gallagher}

of constraints demanding identity in single features between interacting segments. I argue instead that total identity is an explicit requirement of interacting consonants. It is not the composite effect of multiple single feature identities, as is implicit in the original formulation of $\mathrm{ABC}$. There are two arguments in favor of the proposal. First, single feature harmonies of the type required to analyze total identity are systematically unattested. Second, gradient grammaticality patterns reveal a preference for totally identical pairs of consonants, but not for increasingly similar pairs.

Eliminating feature specific harmony constraints has ramifications for the analysis of cases of partial identity like (3). I show that the ABC account of single feature harmonies overgenerates, predicting many unattested patterns. Competing analyses of minor place harmony as local spreading are preferred, supporting the elimination of feature specific harmony constraints. The rest of this paper is organized as follows. Section 1 presents data on total identity requirements and Section 2 presents the $\mathrm{ABC}$ framework. The analysis of total identity within $\mathrm{ABC}$ is discussed in Section 3. In Section 4, I address cases of single feature agreement and Section 5 concludes.

\section{Data: Cases of Total Identity}

In languages with co-occurrence restrictions on similar segments, identical segments may be grammatical. In these languages, identical segments are exceptional. They are not treated by the grammar as maximally similar. In this section, I will present two examples of languages which treat identical consonants as exceptional, Chol and Muna.

\subsection{Chol}

Chol (Aulie and Aulie 1978, Coon and Gallagher 2008) is a Mayan language spoken in Chiapas, Mexico by around 150,000 people.

(4) Chol consonant inventory

\begin{tabular}{|c|c|c|c|c|}
\hline & labial & coronal & velar & glottal \\
\hline implosive & $\mathrm{b}$ & & & \\
\hline plosive & $\mathrm{p}$ & $\mathrm{t}^{\mathrm{j}}$ & $\mathrm{k}$ & $?$ \\
\hline ejective & p' & $t^{\prime} \quad t \int^{\prime} \quad t^{\prime}$ & $\mathrm{k}^{\prime}$ & \\
\hline fricative & & S $\int$ & & $\mathrm{h}$ \\
\hline affricate & & ts ts & & \\
\hline nasal & $\mathrm{m}$ & $\mathrm{n}$ & & \\
\hline approximant & $\mathrm{W}$ & $1 \mathrm{j}$ & & \\
\hline
\end{tabular}

Lexical roots in Chol and other Mayan languages are predominately CVC in shape. The co-occurrence of the five ejective consonants is restricted in Chol. While all ejectives may appear in either initial or final position, two non-identical 
ejectives may not cooccur. Roots with identical ejectives are given in (5a). The hypothetical roots in $(5 \mathrm{~b})$, with non-identical ejectives, are all unattested.

$$
\begin{array}{lll}
\text { a: } & \text { k'ok' } & \text { 'healthy' } \\
\text { ts'uhts' } & \text { 'kiss' } \\
\text { tS'its' } & \text { 'absorb' }
\end{array}
$$

$$
\text { b: } \quad \begin{aligned}
& \text { *k'ats' } \\
& \text { *p'ots' } \\
& \text { *tj'uk' }
\end{aligned}
$$

The pattern in (5) is not unique to Chol. Other languages with laryngeal cooccurrence restrictions that allow identical pairs of consonants include the Mayan languages Tzotzil (Weathers 1947), Yucatec (Straight 1975), Tzutujil (Dayley 1985), as well as Bolivian and Peruvian Aymara (MacEachern 1999).

\subsection{Muna}

Muna (van den Berg 1989, Coetzee and Pater in press) is an Austronesian language spoken in parts of Indonesia. The consonant inventory of Muna is in (6).

(6) Consonant inventory of Muna

\begin{tabular}{l|c|c|c|c|c} 
& labial & coronal & velar & uvular & glottal \\
\hline voiceless & $\mathrm{p}$ & $\mathrm{t}$ & $\mathrm{k}$ & & \\
voiced & $\mathrm{b}$ & $\mathrm{d}$ & $\mathrm{g}$ & & \\
implosive & $\mathrm{6}$ & $\mathrm{d}$ & & & \\
nasal & $\mathrm{m}$ & $\mathrm{n}$ & $\mathrm{g}$ & & \\
voiceless prenasal & ${ }^{\mathrm{m}} \mathrm{p}$ & ${ }^{\mathrm{n}} \mathrm{t},{ }^{\mathrm{n}} \mathrm{S}$ & ${ }^{\mathrm{n}} \mathrm{k}$ & & \\
voiced prenasal & $\mathrm{m}$ & ${ }^{\mathrm{n}} \mathrm{d}$ & ${ }^{\mathrm{n}} \mathrm{g}$ & & \\
voiceless fricative & $\mathrm{f}$ & $\mathrm{s}$ & & в & $\mathrm{h}$ \\
trill & & $\mathrm{r}$ & & & \\
lateral & & $\mathrm{l}$ & & & \\
glide & $\mathrm{w}$ & & & &
\end{tabular}

The vast majority of roots in Muna are either CVCV or CVCVCV ${ }^{2}$. Coetzee and Pater (in press) calculated the Observed/Expected(O/E) ratio (Pierrehumbert 1993, Frisch et al. 2004) of all pairs of consonants in "adjacent" position, those separated only by a vowel. An $\mathrm{O} / \mathrm{E}$ of 1 shows that two consonants cooccur freely. An $\mathrm{O} / \mathrm{E}$ of less than 1 means that the two consonants cooccur less often than expected, showing the effect of some grammatical restriction. An O/E of greater than 1 means that two consonants cooccur more often than expected. Coetzee and Pater's calculations reveal that Muna has a gradient, place based cooccurrence restriction. Within a major place class, two consonants are less likely to cooccur the more subsidiary features (voicing, stricture, sonorancy) they share.

\footnotetext{
${ }^{1}$ Pairs of non-identical ejectives all have an $\mathrm{O} / \mathrm{E}$ of 0 (they are completely unattested). Pairs of non-identical ejectives all have $\mathrm{O} /$ Es of well over 1 .

${ }^{2}$ There are also vowel initial roots, as well as roots with VV sequences.
} 


\section{Gillian Gallagher}

The overall pattern for non-identical consonants can be illustrated by a subset of the labials, given in (7).

(7) Co-occurrence of labials in Muna

\begin{tabular}{c|c|c} 
consonants & $\mathbf{O} / \mathbf{E}$ & disagreeing features \\
\hline $\mathrm{m}-\mathrm{f}$ & 1.04 & continuant, nasal, voice \\
$\mathrm{b}-\mathrm{f}$ & 0.58 & continuant, voice \\
$\mathrm{m}-\mathrm{p}$ & 0.39 & nasal, voice \\
$\mathrm{b}-\mathrm{p}$ & 0.10 & voice \\
$\mathrm{p}-\mathrm{f}$ & 0.07 & continuant \\
$\mathrm{m}-\mathrm{b}$ & 0.07 & nasal
\end{tabular}

In (7), the $\mathrm{O} / \mathrm{E}$ decreases as the number of disagreeing features decreases. In other words, there is an inverse correlation between similarity and degree of attestation.

While highly similar pairs of consonants are very under-attested in Muna, pairs of identical consonants are over-attested, (8).

$$
\text { m-m } 1.24 \quad \text { b-b } 2.79
$$$$
\text { p-p } 1.46
$$

Other languages with place based co-occurrence restrictions which treat identical consonants as exceptional include Javanese (Uhlenbeck 1949, 1950, Mester 1986) and Ngbaka (Thomas 1963, Mester 1986).

\section{ABC: The Framework}

In the $\mathrm{ABC}$ framework, the total identity effect and single feature harmonies are given a unified analysis as effects of correspondence between non-adjacent consonants. Correspondence relations between output consonants are established by CORR-C $\Leftrightarrow \mathrm{C}$ constraints (the definition in (9) is from Rose and Walker 2004:491)

CORR-C $\Leftrightarrow C$ Let $S$ be an output string of segments and let $C_{i} C_{j}$ be segments that share a specified set of features $F$. If $\mathrm{C}_{\mathrm{i}}$, $\mathrm{C}_{\mathrm{j}} \in \mathrm{S}$, then $\mathrm{C}_{\mathrm{i}}$ is in a relation with $\mathrm{C}_{\mathrm{j}}$ : that is, $\mathrm{C}_{\mathrm{i}}$ and $\mathrm{C}_{\mathrm{j}}$ are correspondents of one another.

Rose and Walker propose that CORR-C $\Leftrightarrow \mathrm{C}$ constraints are in a fixed hierarchy. Constraints referring to more similar pairs of consonants outrank those referring to less similar pairs. The partial hierarchy in (10) shows the interaction of place and ejection in stops.

$$
\text { CORR-T' } \Leftrightarrow T^{\prime}>>\text { CORR-T' } \Leftrightarrow T^{\prime}>>\text { CORR-T' } \Leftrightarrow K
$$


The ranking of IO-faithfulness constraints within this hierarchy determines which class of segments are affected by co-occurrence restrictions in a language.

If two segments stand in correspondence, they are required to agree in certain features by constraints from the CC-IDENT[F] family.

$$
\begin{aligned}
& \text { CC-IDENT[F] Let } C_{i} \text { be a segment in the output and } C_{j} \text { be any } \\
& \text { correspondent of } C_{i} \text { in the output. If } C_{i} \text { is }[\alpha F] \text { then } C_{j} \text { is } \\
& {[\alpha F] \text {. }}
\end{aligned}
$$

As illustration, take the analysis of laryngeal agreement in Bolivian Aymara (de Lucca 1987, MacEachern 1999, Rose and Walker 2004). Homorganic stops must have matching laryngeal features $\left({ }^{*} \mathrm{k}^{\prime}-\mathrm{k},{ }^{*} \mathrm{k}^{\mathrm{h}}-\mathrm{k}, \checkmark \mathrm{k}^{\prime}-\mathrm{k}^{\prime}, \checkmark \mathrm{k}^{\mathrm{h}}-\mathrm{k}^{\mathrm{h}}\right)$.

(12) a: homorganic stops must have identical laryngeal features

\begin{tabular}{|l||l|l|l|l|}
\hline \multicolumn{1}{|c|}{$/ \mathrm{k}^{\prime} \ldots \mathrm{k} /$} & CORR-T' $\Leftrightarrow \mathrm{T}$ & CC-IDENT[cg] & IO-IDENT[cg] & CORR-T' $\Leftrightarrow \mathrm{K}$ \\
\hline \hline $\mathrm{k}^{\prime} \mathrm{k}_{\mathrm{x}} \ldots \mathrm{k}^{\prime}{ }_{\mathrm{x}}$ & & & $*$ & \\
\hline $\mathrm{k}_{\mathrm{x}}{ }_{\mathrm{x}} \ldots \mathrm{k}_{\mathrm{y}}{ }_{\mathrm{y}}$ & $* !$ & & $*$ & \\
\hline $\mathrm{k}^{\prime}{ }_{\mathrm{x}} \ldots \mathrm{k}_{\mathrm{x}}$ & & $* !$ & & \\
\hline $\mathrm{k}^{\prime}{ }_{\mathrm{x}} \ldots \mathrm{k}_{\mathrm{y}}$ & $* !$ & & & \\
\hline
\end{tabular}

b: heterorganic stops may disagree in laryngeal features

\begin{tabular}{|l||l:l|l|l|}
\hline \multicolumn{1}{|c|}{$/ \mathrm{k}^{\prime} \ldots \mathrm{p} /$} & CORR-T' $\Leftrightarrow \mathrm{T}$ & CC-IDENT[cg] & IO-IDENT[cg] & CORR-T' $\Leftrightarrow \mathrm{K}$ \\
\hline $\mathrm{k}^{\prime} \mathrm{k}_{\mathrm{x}} \ldots \mathrm{p}_{\mathrm{v}}$ & & & & $*$ \\
\hline $\mathrm{k}^{\prime}{ }_{\mathrm{x}} \ldots \mathrm{p}_{\mathrm{x}}$ & & $* !$ & & \\
\hline $\mathrm{k}^{\prime}{ }_{\mathrm{x}} \ldots \mathrm{p}_{\mathrm{x}}{ }_{\mathrm{x}}$ & & & $* !$ & \\
\hline $\mathrm{k}^{\prime}{ }_{\mathrm{x}} \ldots \mathrm{p}^{\prime}{ }_{\mathrm{y}}$ & & & $* !$ & $*$ \\
\hline
\end{tabular}

In $\mathrm{ABC}$, languages differ from one another on two dimensions: 1. the set of consonants that must correspond (e.g. stridents, homorganic stops, voiceless stops) and 2. the feature in which corresponding segments must agree (laryngeal features, minor place, etc.). In Section 3, I propose to eliminate the second locus of variation by replacing feature specific CC-IDENT[F] constraints with a single, total identity constraint CC-IDENT. Support for this move comes from languages with a total identity requirement. In Section 4 I look at the ramifications of CCIDENT for the analysis of single feature agreement. I show that feature specific CC-IDENT $[\mathrm{F}]$ constraints predict unattested harmony patterns. Many single feature harmonies can be better analyzed as either the effect of the total identity constraint CC-IDENT, or of local spreading (Flemming 1995, Gafos 1999, Ní Chiosáin and Padgett 1997).

\section{Total Identity in $\mathrm{ABC}$}

As originally formulated, interacting consonants in an $\mathrm{ABC}$ analysis are required to agree with one another on a feature by feature basis. A language with total 


\section{Gillian Gallagher}

identity between interacting consonants, then, must have multiple CC-IDENT[F] constraints outranking their IO counterparts. In Chol, for example, ejectives contrast for major place, stridency, and anteriority. Consequently, a feature specific analysis of total identity requires the CC-IDENT[F] constraints in (13).

CC-IDENT[place $] \quad$ CC-IDENT[ $\alpha$ strident $]$

CC-IDENT[ $\alpha$ anterior $]$

(14) Total identity is required between Chol ejectives

\begin{tabular}{|c|c|c|c|c|c|c|c|}
\hline /ts'...k'/ & CORR & $\begin{array}{c}\text { CC- } \\
\text { ID[pl] }\end{array}$ & $\begin{array}{c}\mathrm{CC}- \\
\mathrm{ID}[\mathrm{strid}]\end{array}$ & $\begin{array}{c}\text { CC- } \\
\text { ID[ant] }\end{array}$ & $\begin{array}{c}\text { IO- } \\
\text { ID[pl] }\end{array}$ & $\begin{array}{c}\text { IO- } \\
\text { ID [strid }]\end{array}$ & $\begin{array}{c}\text { IO- } \\
\text { ID[ant] }\end{array}$ \\
\hline${ }^{\sigma} \mathrm{ts}^{\prime}{ }^{\prime} \ldots . . . \mathrm{ts}^{\prime}$ & & & & & * & * & * \\
\hline ts ${ }_{x} \ldots k_{x}$ & & $* !$ & $*$ & $*$ & & & \\
\hline ts $^{\prime}{ }_{\mathrm{x}} \ldots \mathrm{t}^{\mathrm{j}}{ }_{\mathrm{x}}$ & & & $* !$ & * & $*$ & & \\
\hline ts' ${ }^{\prime} \ldots t \int^{\prime}$ & & & & $* !$ & $*$ & $*$ & \\
\hline
\end{tabular}

I propose that total identity is not the result of multiple feature specific constraints. Instead, total identity is explicitly required between corresponding segments by a general, non-feature specific constraint, CC-IDENT, given in (15).

$$
\text { CC-IDENT Given two segments in the output } \mathrm{C}_{\mathrm{i}} \text { and } \mathrm{C}_{\mathrm{j}} \text {, If } \mathrm{C}_{\mathrm{i}} \text { and } \mathrm{C}_{\mathrm{j}}
$$
stand in correspondence, then $\mathrm{C}_{\mathrm{i}}$ and $\mathrm{C}_{\mathrm{j}}$ are identical.

The new analysis of Chol is in (16).

\begin{tabular}{|c|c|c|c|c|c|}
\hline$/ \mathrm{ts}^{\prime} \ldots \mathrm{k}$ '/ & CORR & CC-IDENT & IO-ID[place] & IO-ID[strid] & IO-ID[ant] \\
\hline 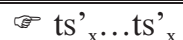 & & & * & * & * \\
\hline ts $^{\prime}{ }_{\mathrm{x}} \ldots \mathrm{k}_{\mathrm{x}}$ & & $* !$ & & & \\
\hline ts $^{\prime}{ }_{\mathrm{x}} \ldots \mathrm{t}_{\mathrm{x}}^{\mathrm{j}}{ }^{\prime}$ & & $* !$ & $*$ & & \\
\hline ts' ${ }_{x}^{\prime} \ldots t \int_{x}^{\prime}$ & & $* !$ & $*$ & $*$ & \\
\hline
\end{tabular}

There are two arguments in favor of the analysis in (16) over that in (14). First, the feature specific CC-IDENT[F] constraints in (14), which are needed to analyze total identity, are independently unmotivated. Second, under the CC-IDENT[F] formulation, there is nothing special about being totally identical as opposed to being partially identical. Gradient effects, as in Muna, reveal a preference for totally identical pairs of consonants, but not for increasingly similar pairs.

\subsection{Some CC-IDENT[F] Constraints are Unmotivated}

If the analysis of Chol in (14) were correct, we should be able to motivate each of the three feature specific CC-IDENT[F] constraints independently. Besides the pattern in Chol, we should see languages with only major place harmony, or only stridency harmony or only anteriority harmony among ejectives. The unattested languages in (17) and (18) are predicted. 


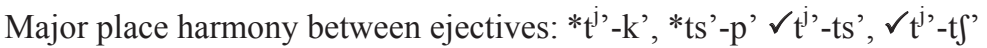

$$
\begin{aligned}
& \text { CC-IDENT[place] }>>\text { IO-IDENT[place] } \\
& \text { IO-IDENT[ } \alpha \text { strid }] \gg>\text { CC-IDENT }[\alpha \text { strid }] \\
& \text { IO-IDENT }[\alpha \text { ant }] \gg>\text { CC-IDENT }[\alpha \text { ant }]
\end{aligned}
$$

$$
\begin{aligned}
& \text { Stridency harmony between ejectives: * } \mathrm{t}^{\mathrm{j}}{ }^{\prime}-\mathrm{ts}^{\prime}, *^{*} \mathrm{t}^{\prime}{ }^{\prime}-\mathrm{t}^{\prime}{ }^{\prime} \checkmark \mathrm{tj}^{\prime}-\mathrm{k}^{\prime} \checkmark \mathrm{ts}^{\prime}-\mathrm{t} \mathrm{f}^{\prime} \\
& \text { CC-IDENT[ } \alpha \text { strid] }>>\text { IO-IDENT }[\alpha \text { strid }] \\
& \text { IO-IDENT }[\alpha \text { ant }] \gg>\text { CC-IDENT[ } \alpha \text { ant }] \\
& \text { IO-IDENT[place] }>>\text { CC-IDENT[place] }
\end{aligned}
$$

The languages in (17) and (18) show major place harmony and stridency harmony between ejectives, respectively. Both major place harmony and stridency harmony are unattested in Hansson's (2001) survey of consonant harmony systems, whether applying to the class of ejectives or to any other class of segments. Moreover, no language restricts the co-occurrence of only some ejectives. In MacEachern's survey of laryngeal co-occurrence restrictions, languages come in two varieties: either all pairs of ejectives (or aspirates or implosives) are prohibited from cooccuring, including identical ones: *k'-p' *k'-k', or only non-identical pairs are disallowed and identical ones are fine: *k'-p', $\checkmark \mathrm{k}$ ' $-\mathrm{k}$ '. The two CCIDENT[F] constraints needed to analyze total identity, CC-IDENT[place] and CCIDENT[strident], are unmotivated.

\subsection{Gradient Co-occurrence Restrictions and Total Identity}

In a feature specific analysis, total identity is an accident. Under the CC-IDENT[F] formulation, there is nothing special about being totally identical as opposed to being partially identical. Looking at languages with a total identity requirement, however, it seems that there is something quite special about being totally identical. In languages with place co-occurrence restrictions, for example, identical pairs of consonants may be allowed while increasingly similar pairs of consonants are increasingly disfavored.

The co-occurrence restrictions in Muna expemplify the exceptional status of identical consonants. In Muna, homorganic consonants are increasingly disfavored the more similar they are. Identical consonants, while maximally similar, are completely grammatical. 
Gillian Gallagher

(19) $\mathrm{O} / \mathrm{E}$ of Muna root consonants

\begin{tabular}{c|c|c} 
consonants & $\mathbf{O} / \mathbf{E}$ & disagreeing features \\
\hline $\mathrm{m}-\mathrm{f}$ & 1.04 & continuant, nasal, voice \\
\hline $\mathrm{b}-\mathrm{f}$ & 0.58 & continuant, voice \\
$\mathrm{m}-\mathrm{p}$ & 0.39 & nasal, voice \\
\hline $\mathrm{b}-\mathrm{p}$ & 0.10 & voice \\
$\mathrm{p}-\mathrm{f}$ & 0.07 & continuant \\
$\mathrm{m}-\mathrm{b}$ & 0.07 & nasal \\
\hline $\mathrm{m}-\mathrm{m}$ & 1.24 & none \\
$\mathrm{b}-\mathrm{b}$ & 2.79 & none \\
$\mathrm{p}-\mathrm{p}$ & 1.46 & none \\
$\mathrm{f}-\mathrm{f}$ & 2.5 & none
\end{tabular}

The feature specific analysis of total identity predicts that a gradient cooccurrence restriction would have exactly the opposite profile from Muna. Increasingly similar pairs of homorganic consonants should be increasingly favored, since they violate fewer CC-IDENT[F] constraints. ${ }^{3}$

(20) Unattested pattern predicted by CC-IDENT[F] analysis

\begin{tabular}{c|c|c} 
consonants & O/E & violates \\
\hline $\mathrm{m}-\mathrm{f}$ & 0 & CC-IDENT[ $\alpha$ voi], CC-IDENT[ $\alpha$ son], CC- \\
& & IDENT $[\alpha$ con $]$ \\
\hline $\mathrm{b}-\mathrm{f}$ & 0.3 & CC-IDENT[ $\alpha$ voice], CC-IDENT $\alpha$ con] \\
$\mathrm{m}-\mathrm{p}$ & 0.3 & CC-IDENT $\alpha$ voice], CC-IDENT[ $\alpha$ son] \\
\hline $\mathrm{b}-\mathrm{p}$ & 0.7 & CC-IDENT $[\alpha$ voice $]$ \\
$\mathrm{p}-\mathrm{f}$ & 0.7 & CC-IDENT $\alpha \alpha$ continuant $]$ \\
$\mathrm{m}-\mathrm{b}$ & 0.7 & CC-IDENT $\alpha \alpha$ sonorant $]$ \\
\hline $\mathrm{m}-\mathrm{m}$ & 1 & none \\
$\mathrm{b}-\mathrm{b}$ & 1 & none \\
$\mathrm{p}-\mathrm{p}$ & 1 & none \\
$\mathrm{f}-\mathrm{f}$ & 1 & none
\end{tabular}

In order to account for attested gradient patterns, the grammar must favor totally identical pairs of consonants without favoring partially identical pairs of consonants. This is possible if there are no feature specific CC-IDENT[F] constraints, but only a single total identity constraint.

\footnotetext{
${ }^{3}$ This of course depends on the theory of gradience in the grammar. I am assuming a model like that developed in Coetzee and Pater (in press), who analyze Muna as a gradient OCP effect with weighted constraints (they do not provide an account of identical consonant grammaticality).
} 


\section{Total Identity in Co-occurrence Restrictions}

\subsection{Summary}

This section has argued that total identity is not the composite effect of multiple single feature harmonies, it is an independent process. The proposed total identity constraint reflects this difference.

In the original $\mathrm{ABC}$ proposal, languages vary in two ways - the set of consonants that must correspond (the CORR-C $\Leftrightarrow \mathrm{C}$ constraints) and the features corresponding segments must agree in (the CC-IDENT[F] constraints). The proposal here eliminates one of these locuses of variation: corresponding segments must always be completely identical. Languages may only differ in what consonants are required to correspond, i.e. the strength of the co-occurrence restriction. In the next section I evaluate the evidence in favor of feature specific constraints.

\section{4. $\quad$ Single Feature Agreement}

The evidence for feature specific CC-IDENT[F] constraints comes from the large number of cases where non-adjacent consonants must agree in a single feature only. The original $\mathrm{ABC}$ proposal is designed to account for a number of cases of long-distance assimilation that do not result in total identity. In these cases, two non-adjacent consonants are required to agree in a single feature that does not spread through intervening segments. In (21) and (22) I give examples of phenomena of this type from Hansson's survey of consonant harmony systems.

(21) Laryngeal agreement: some or all obstruents must have the same laryngeal features, but may differ in place of articulation

$$
\text { Kalabari Ijo (Jenewari 1989) } \quad * d-6, * d-b \quad \checkmark d-b, \sqrt{6}-d
$$

(22) Nasal agreement: an oral consonant is nasal following a root with a nasal.

\begin{tabular}{|c|c|c|}
\hline raka (1) & 1995) & \\
\hline kém-ene & 'to moan' & kéb-ele \\
\hline nók-ene & 'to rain' & lók-ele \\
\hline
\end{tabular}

While phenomena like those above do show long-distance agreement in a single feature, the original formulation of $\mathrm{ABC}$ massively overgenerates. It predicts many unattested harmony patterns and, moreover, fails to explain why certain harmony patterns are common and others completely absent.

The problems with the $\mathrm{ABC}$ account of single feature harmonies is best shown by looking at minor place harmonies. Many of the single feature harmonies that result in partial identity involve agreement in a minor place specification. Coronal harmonies, as in Chumash, are the most prevalent example. Navajo has a similar pattern, alveolar and alveopalatal stridents may not cooccur.

(23) Navajo (Hansson 2001:7 and references therein):

$\begin{array}{ll}\text { fí-t } \mathrm{ti}: \mathrm{h} & \text { 'my nose' } \\ \text { si-ts'a:? } & \text { 'my basket' } \\ \text { si-zid } & \text { 'my scar' }\end{array}$




\section{Gillian Gallagher}

Minor place harmonies all share an important property: they have been analyzed as local agreement. Flemming (1995), Ní Chiosáin and Padgett (1997) and Gafos (1999) show that minor place specifications may spread through intervening segments without any acoustic consequences. They analyze these apparent cases of non-local assimilations as local assimilations. The action-at-a-distance in minor place harmonies is then only apparent: assimilation is local, but has no audible effect on segments that don't contrast for the spreading feature.

A CC-IDENT[F] analysis predicts that stridents or coronals should be able to harmonize for any feature, or any combination of features. Beyond the wellattested minor place harmonies shown above, we also predict languages where stridents must agree in continuancy but not minor place (24), or in both minor place and voicing (25).

$$
\begin{aligned}
& * \text { s-ts, } * \int-t \int \quad \checkmark \text { ts-t } \int, \checkmark \text { s- } \int \\
& *_{\mathrm{s}-\mathrm{Z}} \quad *_{\mathrm{s}-} \int \quad \checkmark_{\mathrm{s}-\mathrm{ts}}
\end{aligned}
$$

The predictions in (24) and (25) are not borne out. Coronal harmonies are overwhelmingly minor place harmonies, other contrastive features like voicing and stricture are ignored. This is predicted in a spreading analysis, since voicing and stricture cannot spread unnoticed through intervening segments.

The current proposal predicts that coronal harmonies should either be minor place harmonies, or total identity effects. Indeed, cases of total identity appear to be the only ones that involve multiple harmonies. In Chol and other Mayan languages stridents are required to agree for both anteriority and continuancy, the result of which is total identity.

$$
\begin{aligned}
& \text { Total identity (=agreement in [ } \alpha \text { anterior }] \text { and }[\alpha \text { continuant }] \text { ) }
\end{aligned}
$$

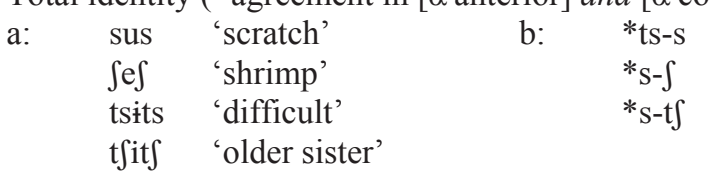

In the original $\mathrm{ABC}$ proposal, both the set of consonants that must stand in correspondence and the harmonizing feature are independently variable. Consequently, we should find languages that have minor place harmony between only a sub-set of the possible targets.

$$
\begin{array}{ll}
\text { a: } & \text { CORR[-continuant], CC-IDENT[ } \alpha \text { anterior] }>>\text { IO-IDENT } \\
\text { b: } & * \text { ts-t } \int \text { s- } \int
\end{array}
$$

If there are no feature specific harmony constraints, then the only range of variation is in the set of consonants that must be in correspondence. This seems to be a good prediction. In Chol, total identity is only required between a sub-set of the 
stridents, depending on their similarity. Plain stridents must be totally identical to cooccur. An ejective strident and a fricative, however, may cooccur.

Total identity is not required of all stridents in Chol
sits' 'stretch'
$\begin{array}{ll}\text { sits' 'saliva' } & \text { tof 'of 'worm' }\end{array}$

While there aren't any languages that pick out a sub-set of the stridents for minorplace harmony, there are languages that pick out a sub-set of the stridents for total identity.

The feature specific CC-IDENT[F] proposal generalizes to the lowest common denominator. It accounts for (21) and (22) at the expense of accounting for anything. The challenge for future research is to find an alternative explanation for phenomena like (21) and (22) without resorting to feature specific CCIDENT[F] constraints.

\section{Conclusion}

In this talk I have argued that total identity requirements are formally distinct from partial identity requirements. Total identity must be the result of a general, non-feature-specific constraint. The feature specific constraints needed to account for total identity are unmotivated. Feature specific constraints cannot account for gradient co-occurrence restrictions. Eliminating feature specific CC-IDENT[F] constraints has desirable consequences for the analysis of minor place harmonies. CC-IDENT[F] constraints make unattested typological predictions that an analysis with only spreading and total identity does not.

\section{References}

Applegate, Richard B. 1972. Ineseño Chumash grammar. Ph.D. diss., University of California, Berkeley.

Aulie, Wilbur and Evelin Aulie. 1978. Diccionario Ch'ol-Español, EspañolCh'ol. México: Summer Institute of Linguistics.

van den Berg, René. 1989. A Grammar of the Muna Language. Foris, Dordrecht.

Coetzee, Andries W and Joe Pater. in press. Weighted constraints and gradient restrictions on place co-occurrence in Muna and Arabic.

Coon, Jessica and Gillian Gallagher. 2007. Similarity and correspondence in Chol Mayan. Talk presented at North East Linguistic Society 38, Ottawa, ON.

Cowan, Marion. 1969. Tzotzil grammar. In Summer Institute of Linguistics Publications. Norman: University of Oklahoma.

Dayley, Jon. 1985. Tzutujil grammar. Berkeley: University of California Press.

Frisch, Stefan, Janet Pierrehumbert, and Michael Broe. 2004. Similarity avoidance and the OCP. Natural Language and Linguistic Theory 22:179-228. 
Gillian Gallagher

Gafos, Adamantios. 1999. The articulatory basis of locality in phonology. New York: Garland.

Hansson, Gunnar Olafur. 2001. Theoretical and typological issues in consonant harmony. Ph.D. diss., University of California, Berkeley.

Hyman, Larry. 1995. Nasal consonant harmony at a distance: the case of Yaka. Studies in African Linguistics 24:5-30.

Jenewari, Charles E.W. 1989. Ijoid. In John Bendor-Samuel ed. The Niger-Congo languages, 105-118. Lanham: University of Press America.

Kaufman, Terrence. 1971. Tzeltal phonology and morphology. In University of California Publications in Linguistics, 61. Berkeley: University of California Press.

de Lucca, Manuel. 1987. Diccionario practico aymara-castellano castellanoaymara. Chochabamba: Los Amigos del Libro.

MacEachern, Margaret. 1999. Laryngeal co-occurrence restrictions. New York: Garland.

Mester, R. Armin. 1986. Studies in tier structure. Ph.D. diss., University of Massachusetts, Amherst.

Ní Chiosáin, Máire, and Jaye Padgett. 1997. Markedness, segment realization, and locality in spreading. Technical Report LRC-07-01, Linguistics Research Center, University of California, Santa Cruz.

Pierrehumbert, Janet. 1993. Dissimilarity in Arabic verbal roots. In A. Schafer ed., Proceedings of NELS 23:367-381.

Rose, Sharon, and Rachel Walker. 2004. A typology of consonant agreement as correspondence. Language 80:475-531.

Straight, H. Stephen. 1976. The acquisition of Maya phonology: Variation in Yucatec child language. New York: Garland.

Thomas, Jacqueline M.C. 1963. Le parler Ngbaka de Bokanga: Phonologie, morphologie, syntaxe. Paris: Mouton.

Uhlenbeck, E. M. 1949. De structuur van het Javaanse morpheem. Bandoeng: Nix \& Co.

Uhlenbeck, E.M. 1950. The structure of the Javanese morpheme. Lingua 2:23970.

Weathers, Nadine. 1947. Tsotsil phonemes with special reference to allophones of b. International Journal of American Linguistics 13:108-111.

Gillian Gallagher

Massachusetts Institute of Technology

Department of Linguistics and Philosophy, 32D-808

77 Massachusetts Avenue

Cambridge, MA 02139

gilliang@mit.edu 